\section{Natural resources and civil conflict: an overview of controversies, consensus, and channels}

Anouk S. Rigterink

C6 'Diamonds are a guerrilla’s best friend.” This sums up what has become a popular conception: natural resources cause civil conflict. In no small part, this conception arose from quantitative research into the relationship between natural resource abundance and civil war onset. This article reviews this literature. It argues that evidence in support of a causal link between war onset and the presence of natural resources as a single category is fragile. More robust evidence exists for a connection between violent conflict and the abundance of specific resources, such as diamonds or oil. However, debate on the exact mechanisms through which resources would cause civil war is all but settled. A number of interesting theoretical models that go into this have recently been constructed, although not all of them have been tested empirically. Research into the exact processes connecting resources and violence is highly important for designing and evaluating the chances of success of various policy interventions, such as the Kimberley process and the Extractive Industries Transparency Initiative.

This article is organized as follows. The first section reviews empirical evidence on the causal link between natural resources as a single category and civil conflict onset, including challenges and controversies. The second section will do the same with respect to the link between oil and diamonds and war start. The third section goes into mechanisms and policy implications. The fourth section concludes.

Natural resources as a single category

Similar models, different conclusions

Studies by Collier and Hoeffler and by Fearon and Laitin pioneered quantitative research into the causes of civil war. ${ }^{2}$ Studies of this type have a number of elements in common: they try to explain the onset of civil war, usually taking the form of a binary variable indicating whether a civil war started in a given country in a given time period. This variable can be taken from a number of different databases on war, most notably the Correlates of War Project and the UCP/PRIO Conflict Dataset. A crucial element of the definition of war is that it has to cause a given number of "battle-related deaths" (one thousand or twenty-five are common threshold levels). Natural resource abundance is one of the explanatory variables in these models, measured as the value of natural resource exports as a percentage of GDP, a measure usually termed sxp. This measure does not distinguish among different types of resources, but takes agricultural exports, exports of renewable resources, such as timber, and mineral resources, like oil and metals, as a single category.

Despite similarities in their models, Collier and Hoeffler and Fearon and Latin reach different conclusions. According to the first pair of authors, resource abundance (measured as sxp) is strongly related to the chances of civil war onset. This relationship is robust to controlling for oil exports over GDP and is found to be shaped like an inverted "u": absence of substantial amounts of resources decreases incentives to fight, medium levels of resource abundance are found to greatly increase war risk, and extremely high levels would earn so much revenue for the government that rebellion becomes infeasible. In Fearon and Latin's model however, $\operatorname{sxp}$ is unrelated to war onset. Instead, a binary variable for oil-

producing countries is weakly statistically significant, albeit this relationship is linear: war risk increases with the amount of resources present, irrespective of whether a country has low, medium, or high levels of these. The conclusion is that there is no relationship between resource abundance and war, and if there is one, it is mainly driven by the presence of oil resources.

\section{Controversies}

What can account for these different conclusions? On the one hand, a number of technical issues are cited in this context. ${ }^{3}$ First, there is the issue of how to treat ongoing wars: should country-periods with continuing wars be omitted from the sample or would it be better to code them as having no war start, controlling for conflict in the previous year? Second, Collier and Hoeffler use 5-year periods as the unit of analysis, whereas Fearon and Laitin work with yearly data. It can be argued that using 5-year periods results in inconsistent lag times (variables are lagged to the beginning of the period) and inconsistent treatment of quickly renewed wars, 
especially when ongoing wars are omitted from the sample. A war starting in quick succession of another may then arbitrarily be coded as missing data or a new war start, depending on whether a period end falls in between. Third, as data from conflict zones is highly erratic, authors have to choose between imputing data or accepting a large loss of observations. It has indeed been shown that the Collier and Hoeffler analysis is sensitive to imputing data, changing the coding of ongoing wars, and using yearly data instead of five-year periods. ${ }^{4}$

Fragility of results on war onset and natural resources treated as a single category seems to go significantly further than this. Analyses of the causes of war in general are sensitive to the choice of war database. Although these databases are generally trying to quantify the same phenomenon using similar criteria, correlations between them are surprisingly low. Highly unreliable reporting of "battle-related deaths," treatment of conflicts that dip below the death threshold for a short period of time and then exceed it again, and death counts that are not proportional to the country population are important issues here. Surprisingly few explanatory variables are consistently related to war in multiple databases, and resource abundance is not one of them. ${ }^{5}$ But even when using the same database (there seems to be a consensus to take the UCP/PRIO database as a benchmark), the choice and source of control variables matters. For example, measures of natural resource abundance in the Collier and Hoeffler and Fearon and Laitin analyses cannot be interchanged without a loss of statistical significance. ${ }^{6}$ Exploring this in a more systematic way is an analysis identifying 88 possible explanatory variables and regressing every possible combination of four of these on the same war database (using a casualty threshold of one thousand). Given the distribution of results on six measures of resource abundance identified, the hypothesis of no relationship to war is not rejected for any of them. ${ }^{7}$

Even if a robust statistical relation between natural resources and civil war could be established, there is still the question of whether we can conclude there is a causal relationship. The way in which natural resource abundance is quantified, as quantity exported over GDP, is problematic in this respect. Problems may take the form of reversed causality. Companies that can be moved may feasibly flee a country in anticipation of war, decreasing GDP, while natural resource extracting companies are location bound and may maintain production. This may increase the ratio of resource exports to GDP as a consequence of war threat, rather than the other way around. ${ }^{8}$ Alternatively, one might wonder what sxp is actually measuring: resource abundance or resource dependence. The latter may be related to irresponsible government policy or an economy "in bad shape," and both factors could feasibly be related to war risk. Indeed, using the stock of natural resources (which is subject to these problems to a lesser extent) either as a measure of resource abundance directly, or as an instrument for resource dependence, has led to the conclusion that there is no evidence for a causal link between natural resources and war. ${ }^{9}$

In sum, the causal relationship between natural resources as a single category and war risk is fragile. Changes in the technical specification of the models, war database, and control variables used can significantly alter conclusions drawn and it is unclear whether correlations observed indeed imply causality.

"Rogue resources": oil and diamond abundance

Another strand of research considers the impact of abundance of specific resources on civil conflict. This is partly a response to nonrobust results when taking natural resources as a single category and partly a result of case study evidence suggesting that different types of resources have different effects on different types of war. The argument here is that the type of extraction matters: is the resource extracted at one geographic point or can extraction occur in dispersed locations? ${ }^{10}$ Some resources can be examples of both, such as diamonds, which can either be found dispersed in river beds ("secondary diamonds") or concentrated in mining sites ("primary diamonds"). The hypothesis is that point-extracted resources in a specific region would lead to separatist war, point-extracted resources off territory (such as off-shore oil) to strive for control of the government, and dispersed resources to prolonged rebellion, with rebels controlling parts of the territory for long periods of time.

Even though this idea could potentially apply to many types of resources, oil and diamonds are the resources that are most often connected to conflict, especially in the quantitative literature. In this context, an advantage of focusing on a specific resource is that absolute production data can be used, rather than export data relative to GDP. This mitigates worries with respect to causality, at least to some extent.

In general, authors seem to agree that oil and diamond abundance are robustly related to at least some types of conflict. ${ }^{11}$ However, the hypotheses outlined above are not always neatly confirmed by the data. A leading study on diamond abundance uses binary variables for the production of primary and secondary diamonds, the first type being an example of a point-extracted resource and the second type being more dispersed. ${ }^{12}$ The study concludes that the most robust relationship found is the one between secondary diamonds and ethnic war onset (although the definition of ethnic war is slightly unclear). ${ }^{13}$ In contrast, another study, using diamond production per capita, finds that only primary diamonds are related to conflict onset in general. Surprisingly, secondary diamonds are related to separatist conflict in the analysis. In 
the case of oil, this study concludes that onshore oil production is related to increased risk of war of all types. Consistent with the hypotheses outlined above, off-shore oil is not correlated to separatist conflict, whereas onshore oil is. Off-shore oil is related to national and nonethnic conflict in the analysis. ${ }^{14}$

Overall, the consensus is that there is substantive evidence that oil and diamond abundance are related to conflict, with the evidence on oil being more robust than that on diamonds. Differing and sometimes counterintuitive relationships between different types of war and point-extracted and dispersed types of oil and diamonds have given rise to the question of mechanism: through which process do resources lead to increased war risk?

\section{Mechanisms and policy implications}

The mechanics of the resources-war link

There is no shortage of potential ways in which resource abundance and conflict could be linked. (Humphreys speaks of "an embarrassment of mechanisms.") However, determining which mechanism is supported by the data has proven to be a difficult task. As highlighted, differences between point-extracted and dispersed resources might shed some light on the matter, but results are not always conclusive. While some refine empirical techniques, others call for a more rigorous theoretical basis for analysis. The critique on the studies described here is that they are looking for correlations first and then go no further than constructing post-hoc hypotheses on the mechanisms through which they might operate. A preferred way to do analysis would be to first construct a (mathematical) theoretical model making the mechanisms explicit, derive hypotheses, and then proceed to test these in the data. ${ }^{15}$ Recently, a number of these formal models have been developed, going deeper into the question of mechanism. However, some of these remain theoretical in the sense that they have not been tested using data.

The real or putative link between resources and war is one of the most important arguments in the "greed vs. grievance" debate. The central question of this debate is whether the motivation for war is "economic" (usually understood as a result of cost-benefit analysis) or political/ideological (a clearly formulated grievance against the government in charge). Collier and Hoeffler interpreted the strong correlation between resources and war as evidence for a greed mechanism: when valuable resources are present in a country, one can always find individuals willing to fight to obtain them. For these rebels, profits from natural resources might either materialize during wartime or they might constitute a "prize" obtained upon taking over government. But, other authors point out, grievance could also be the mechanism connecting natural resource abundance and violence. Natural resource abundance could lead to grievances among citizens in a number of ways. Extracting them could cause environmental damage, the perception might exist that the proceeds are not fairly distributed, governments might be inclined to take harsher preemptive action against separatism in resource-rich parts of their territory, angering citizens in the process, or the presence of natural resources might strengthen regional identities. ${ }^{16}$

Even though "greed vs. grievance” has become part of the vocabulary of research into war, the consensus seems to be that the dichotomy is not always useful. It is argued that the decision to rebel will always be some combination of "greed" and "grievance," as even the most ideologically motivated rebellion will have to finance itself somehow. Following this line of reasoning, even the "intellectual parents" of the greed vs. grievance dichotomy have moved away from it, hypothesizing that the mechanism connecting resources and civil war is opportunity rather than greed. The argument here is that in any society, some groups of people will have grievances. Whether they are able to act upon these, however, would depend on the opportunities to finance a rebellion. Natural resources are said to constitute such an opportunity.

So three potential mechanisms explaining a correlation between resources and war are: greed, which comes in two variations_-resources as revenue when fighting and resources as a premium on winning government-and grievance. Formal models of resources and war are all "economic" in the sense that they assume that rebellion will occur if the benefits outweigh the costs, and they go deeper into these mechanisms. Focusing on resources as revenue, it is possible to see a country as consisting of multiple groups commanding safe resources and consider natural resources as contested. The groups then have to choose whether to use their safe resources for productive activities or fighting activities, the latter with the goal to obtain part of the contested natural resources with some probability. Conflict risk in this model will increase with the amount of natural resources and the extent to which they are contested. If the country is a net exporter of the natural resource, opening up to trade will equally increase conflict risk, as the price of the natural resource on the world market is higher than the price under autarky. Conflict risk will decrease when the returns to productive activities increase relative to returns to fighting. ${ }^{17}$

Alternatively, it is possible to model resources as influencing the costs of staging a rebellion, where labor is modeled as the largest expense. Some processes of natural resource extraction can be considered capital-intensive and an increase in the capital-intensity of production would lead to lower returns to labor. Lower returns to labor then lead to lower costs of hiring rebels, increasing the chances of conflict. ${ }^{18}$ In contrast to the previous model, this one has been tested empirically in the context of Colombia, and it has been found that an increase in the price of coffee (a labor-intensive natural resource) is correlated to lower levels of violence, whereas an increase in the price of oil (extracted through a capital-intensive process) is associated with more violence. $^{19}$

Natural resources can also be modeled as a premium upon winning the government. The incentive to unlawfully take over the government will then increase with the value of natural resource revenue. An interesting feature of this type of model is that it can include institutions that limit the extent to which a government can 
distribute the revenue at its own discretion. If institutions are so strong that the government cannot distribute more income to its favored group than to other groups, natural resource abundance does not increase the incentive to stage a conflict. Indeed, this effect can be shown to exist in cross-country data, taking the price of selected natural resources as an explanatory variable. ${ }^{20}$

Other potential mechanisms featuring prominently in the literature include weak governance and low economic growth. An often-heard argument is that governments that derive large revenues from natural resource exports need to raise less tax revenue. This, in turn, is presumed to decrease the accountability of the government to its citizens, which might fuel war against it. A smaller need to tax also decreases the need for the government to actually control its territory, making war more feasible.

The idea that natural resource abundance will lead to slow growth-the resource curse - forms the basis for the last potential mechanism. A high rate of natural resource exports could drive up the exchange rate and the prices of nontradable goods, rendering the manufacturing sector less competitive (a phenomenon called the Dutch Disease). Low economic growth might in turn translate into dissatisfaction with the government and/or lower the opportunity costs of being a rebel.

In terms of formal modeling, both lines of reasoning are slightly problematic. In order to arrive at the conclusion that governments will raise less tax when they receive revenue in the form of resource rents, one has to assume that governments do not maximize revenue, but that they are revenue satisficers. This goes against standard theoretical practice. Furthermore, empirical evidence on the existence of Dutch Disease is meager at best. Combining both mechanisms, and the one on resources as a premium on forming the government, is a model that assumes that large resource rents increase the incentive to stage a coup. This decreases the expected time in office of the incumbent, thereby increasing its discount rate. If this rate is sufficiently high, the incumbent has no incentive to invest in public goods that will bring economic growth in the medium to long term. The result is a predatory incumbent and slow economic growth due to underinvestment. ${ }^{21}$ Unfortunately, this model has yet to be tested empirically.

Concluding, resource abundance could increase war risk through its impact on the benefits of rebellion (either during the war or upon taking over the government), the cost of rebellion, grievance, the quality of the government in terms of public goods delivered, and its impact on economic growth. However, these mechanisms can be conditional on other factors, such as the quality of institutions. Empirically, there is some evidence in support of some of these mechanisms, although others have not yet been subjected to empirical testing.

\section{Policy implications}

The question of mechanisms is important not only from an academic, but also from a policymakers' point of view. To design effective interventions, the latter need to know the process/es through which resource abundance leads to violence. Different conceptions of this process can be discerned when looking at different policy initiatives.

The Kimberley process, for example, tries to limit the extent to which diamonds from conflict zones can be traded internationally. The underlying thought here seems to be that diamonds constitute revenue for rebels and that by diminishing their tradability their price will go down. Indeed, the website of the Kimberley process explicitly states that "rough diamonds [are] used by rebel movements to finance wars against legitimate governments". ${ }^{22}$ Interestingly, cross-country empirical evidence for this mechanism (resources as revenue while fighting) is scarce. Studies distinguishing between primary and secondary diamonds arrive at conflicting results, as emphasized in the previous section. Another interesting point is that the incentives that are created by diamond revenues flowing to governments are not addressed by the Kimberley process even though these are central in a number of the other mechanisms outlined. Lastly, the initiative only acts when countries are already in conflict, while other mechanisms highlight the possibility that diamond revenues increase the incentive to fight irrespective of whether a conflict has already started.

Another prominent policy initiative is the Extractive Industry Transparency Initiative (EITI). Judging by its website, the initiative aspires to "make resources benefit all." It mentions that natural resource revenues can lead to growth in the presence of good governance, which it aims to contribute to through promoting transparency and accountability. ${ }^{23}$ This view seems to confirm the bad governancelow economic growth mechanism, although it should be noted that EITI does not explicitly state that decreasing conflict risk is one of its goals. Although this particular model has not yet been empirically tested, good governance or institutional quality features in a number of mechanisms. There is some empirical evidence that resource abundance leads to conflict and/or low economic growth in the presence of low quality institutions, while it leads to improved outcomes in high quality institutional environments. ${ }^{24}$ Even so, the extent to which transparency and accountability can improve institutional quality may be limited. Promoting transparency and accountability could feasibly constrain the ability of the government to distribute benefits from resources exclusively to itself and/or its cronies and thus decrease the prize upon winning the government. The studies cited, however, used a broader conception of institutions, considering property rights or strength of government in general, not just in the context of resource policy. If institutions that are not directly resource-related indeed matter, then efforts to improve their quality would equally have to have a broader outlook.

Taking a final look at the list of mechanisms, resource abundance as decreasing the returns to labor and hence the cost of rebellion has not yet been explored. To my knowledge, there is no global policy initiative exploiting this mechanism. If it is indeed at play, it may be possible to reduce the level of violence by setting up projects that employ a significant number of people in unstable regions. This idea seems to 
(C) www.epsjournal.org.uk - Vol. 5, No. 2 (2010)

partly motivate efforts by the U.S. military in Iraq and Afghanistan where a fund is available to local army commanders to start reconstruction projects that "employ many people from the local population." 25 As there is some evidence that increasing employment and thus the cost of labor decreases violence, this strategy appears to have potential.

\section{Conclusion}

Looking at cross-country, quantitative research into the relationship between resource abundance and civil war onset we can say that evidence for such a link is quite fragile when taking resources as a single category. Results are sensitive to changing specifications and are subject to concerns about causality. Evidence for a link between specific resources, notably oil and diamonds, are more robust, although hypotheses about the differences between point-extracted and dispersed resources are not always confirmed by the data. Lastly, the discussion on which (combination of) mechanism(s) links natural resource abundance and conflict risk has not been settled. Resources can be conceptualized as revenue during war, as a premium on winning government, as decreasing the cost of hiring rebels, and as causing grievance, weak governance, and slow economic growth. There is evidence for some of these mechanisms while others have yet to be tested empirically. From a policy standpoint, the question of channel is especially important: different mechanisms inform different policy options. Assessing and predicting their success can be helped by more research in this field.

\section{Notes}

Anouk S. Rigterink is a PhD candidate at the Development Studies Institute, London School of Economics and Political Science, U.K. Contact: a.s.rigterink@lse.ac.uk.

1. Malaquias (2001, p. 15).

2. Collier and Hoeffler (1998; 2004); Collier, et al. (2009); Fearon and Laitin (2003).

3. Fearon (2005).

4. Elbadawi and Sambanis (2002).

5. Sambanis (2005).

6. Humphreys (2003); later published as Humphreys (2005).

7. Hegre and Sambanis (2006).
8. Ross (2004b).

9. Brunnschweiler and Bulte (2009); Rigterink (2010).

\section{Le Billon (2004).}

11. See, e.g., Humphreys (2005).

12. See Bulanova (1995).

13. Lujala, et al. (2005).

14. Ross (2006).

15. For an example of this critique and an excellent and up-to-date overview of empirical analyses of civil conflict, see Blattman and Miguel (2010).

16. For an overview of potential mechanisms and a number of interesting case studies, see Ross (2004a).

17. Garfinkel, et al. (2008).

18. Dal Bó and Dal Bó (2004).

19. Dube and Vargas (2009).

20. Besley and Persson (2008).

21. For this model and mentioned critiques, see Caselli (2006).

22. See www.kimberleyprocess.com [accessed 27 May 2010].

23. See www.eiti.org [accessed 27 May 2010].

24. See, e.g., Besley and Persson (2008); Mehlum, et al. (2006); Rigterink (2010).

25. See, e.g., http://usacac.army.mil/cac2/call/docs/09-27/ch-4.asp [accessed 2 June 2010]. Data on this program, the Commander's Emergency Response Program (CERP), has been used by a number of authors, for example Berman, et al. (2008). This paper finds a statistically significant negative relationship between CERP spending and insurgency activity. 


\section{References}

Berman, E., J. N. Shapiro, et al. 2008. "Can Hearts and Minds be Bought? The Economics of Counterinsurgency in Iraq.” Boston: National Bureau of Economic Research. NBER Working Paper \#14606. http://www.nber.org/papers/w14606.

Besley, T. and T. Persson 2008. “The Incidence of Civil War: Theory and Evidence.” NBER Working Paper \#w14585. Also see http://papers.ssrn.com/sol3/papers.cfm? abstract_id=1320831.

Blattman, C. and E. Miguel. 2010. “Civil War.” Journal of Economic Literature. Vol. 48, No. 1, pp. 3-57.

Brunnschweiler, C. and E. H. Bulte. 2009. "Natural Resources and Violent Conflict: Resource Abundance, Dependence and the Onset of Civil Wars.” Oxford Economic Papers. Vol. 61, pp. 651-674.

Bulanova, G.P. 1995. “The Formation of Diamond.” Journal of Geochemical Exploration. Vol. 53, pp. 1-23.

Caselli, F. 2006. "Power Struggles and the Natural Resource Curse.” Unpublished working paper. See http://eprints.lse.ac.uk/4926/.

Collier, P. and A. Hoeffler. 1998. “On Economic Causes of Civil War.” Oxford Economic Papers. Vol. 50, pp. 563-573.

Collier, P. and A. Hoeffler. 2004. "Greed and Grievance in Civil War.” Oxford Economic Papers. Vol. 56, pp. 563-595.

Collier, P., A. Hoeffler, et al. 2009. "Beyond Greed and Grievance: Feasibility and Civil War.” Oxford Economic Papers. Vol. 61, pp. 1-27.

Dal Bó, E. and P. Dal Bó. 2004. "Workers, Warriors and Criminals: Social Conflict in General Equilibrium.” Providence, RI: Brown University Economics Working Paper \# 2004-10. See http://papers.ssrn.com/sol3/papers.cfm?abstract_id=594562.

Dube, O. and J. Vargas 2009. “Commodity Price Shocks and Civil Conflict: Evidence from Colombia.” Working Paper. See http://econ.as.nyu.edu/docs/IO/13746/ Commodity_shocks_civil_conflict.pdf.

Elbadawi, I. and N. Sambanis. 2002. "How Much War Will We See? Explaining the Prevalence of Civil War.” Journal of Conflict Resolution. Vol. 46, No. 3, pp. 307-334.

Fearon, J. 2005. “Primary Commodities Exports and Civil War.” Journal of Conflict Resolution. Vol. 49, No. 4, pp. 483-507.

Fearon, J. and D. Laitin. 2003. "Ethnicity, Insurgency and Civil War.” American Political Science Review. Vol. 97, No. 1, pp. 75-90.

Garfinkel, M., S. Skaperdas, et al. 2008. “Globalization and Domestic Conflict.” Journal of International Economics. Vol. 76, pp. 269-308.

Hegre, H. and N. Sambanis. 2006. "Sensitivity Analysis of Empirical Results on Civil War Onset.” Journal of Conflict Resolution. Vol. 50, No. 4, pp. 508-535.

Humphreys, M. 2003. "Natural Resources, Conflict and Conflict Resolution.” Working paper.
Humphreys, M. 2005. "Natural Resources, Conflict and Conflict Resolution. Uncovering the Mechanisms.” Journal of Conflict Resolution. Vol. 49, No. 4, pp. 508-537.

Le Billon, P. T. 2004. “The Geopolitical Economy of 'Resource Wars'.” Geopolitics. Vol. 9, No. 1, pp. 1-28.

Lujala, P., N. P. Gleditsch, et al. 2005. “A Diamond Curse? Civil War and a Lootable Resource.” Journal of Conflict Resolution. Vol. 49, No. 4, pp. 538-562.

Malaquias, A. 2001. "Diamonds are a Guerrilla's Best Friend: The Impact of Illicit Wealth on Insurgency Strategy.” Third World Quarterly. Vol. 22, No. 3, pp. 311.325.

Mehlum, H., K. Moene, et al. 2006. “Institutions and Resource Curse.” The Economic Journal. Vol. 116, pp. 1-20.

Rigterink, A. S. 2010. "The Wrong Suspect: An Inquiry into the Endogeneity of Natural Resource Measures to Civil War.” London: London School of Economics and Political Science. See http://www.csae.ox.ac.uk/conferences/2010-EdiA/ papers/191-Rigterink.pdf.

Ross, M. 2004a. "How do Natural Resources Influence Civil War? Evidence from Thirteen Cases.” International Organization. Vol. 58, No. 1, pp. 35-67.

Ross, M. 2004b. "What do we Know about Natural Resources and Civil War?” Journal of Peace Research. Vol. 41, No. 3, pp. 337-356.

Ross, M. 2006. “A Closer Look at Oil, Diamonds and Civil War.” Annual Review of Political Science. Vol. 9, pp. 265-300.

Sambanis, N. 2004. "What is Civil War? Conceptual and Empirical Complexities of an Operational Definition.” Journal of Conflict Resolution. Vol. 48, No. 6, pp. 814-858. 